Supporting Information for:

\title{
Functional characterization of cholera toxin inhibitors using human intestinal organoids.
}

Domenique D. Zomer-van Ommen, ${ }^{\ddagger}$ Aliaksei V. Pukin, ${ }^{\S} \mathrm{Ou} \mathrm{Fu},{ }^{\S}$ Linda H.C. Quarles van Ufford ${ }^{\S}$ Hettie M. Janssens, ${ }^{\|}$Jeffrey M. Beekman, ${ }^{\ddagger}$ Roland J. Pieters ${ }^{\star \S}$

${ }^{\ddagger}$ Department of Pediatric Pulmonology, University Medical Centre Utrecht, Lundlaan 6, 3508 GA, Utrecht, the Netherlands;

${ }^{\S}$ Department of Chemical Biology \& Drug Discovery, Utrecht Institute for Pharmaceutical Sciences, Utrecht University, P.O. Box 8oo82, 3508 TB Utrecht, The Netherlands;

"Department of Pediatric Pulmonology, Erasmus Medical Center/Sophia Children's Hospital, Wytemaweg 8o, 3015 CN, Rotterdam, The Netherlands 
Table of Contents

S3 Synthetic Scheme

S4 NMR spectra 


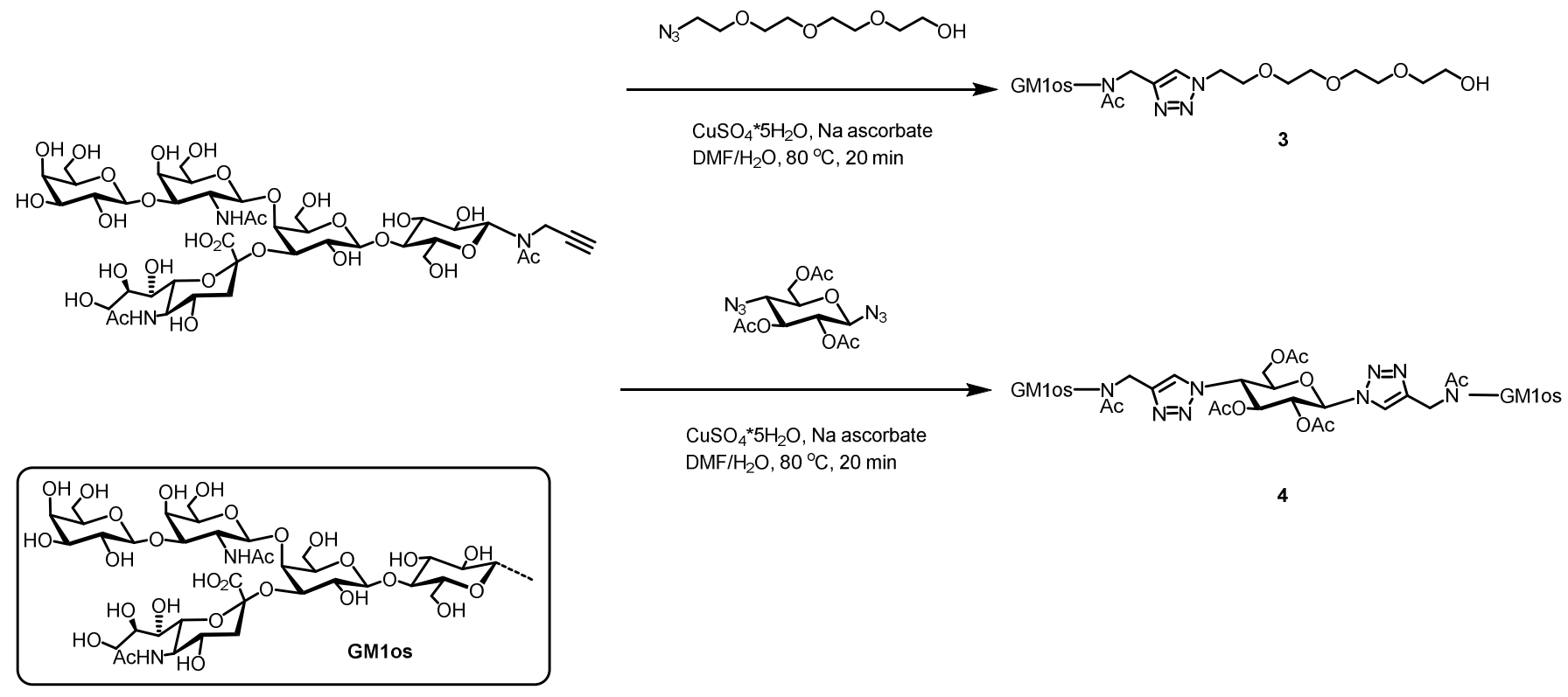


${ }^{1} \mathrm{H}$ NMR Spectrum of the monovalent inhibitor $3\left(500 \mathrm{MHz}, \mathrm{D}_{2} \mathrm{O}\right)$ 
${ }^{1} \mathrm{H}$ NMR Spectrum of the bivalent inhibitor $4\left(500 \mathrm{MHz}, \mathrm{D}_{2} \mathrm{O}\right)$

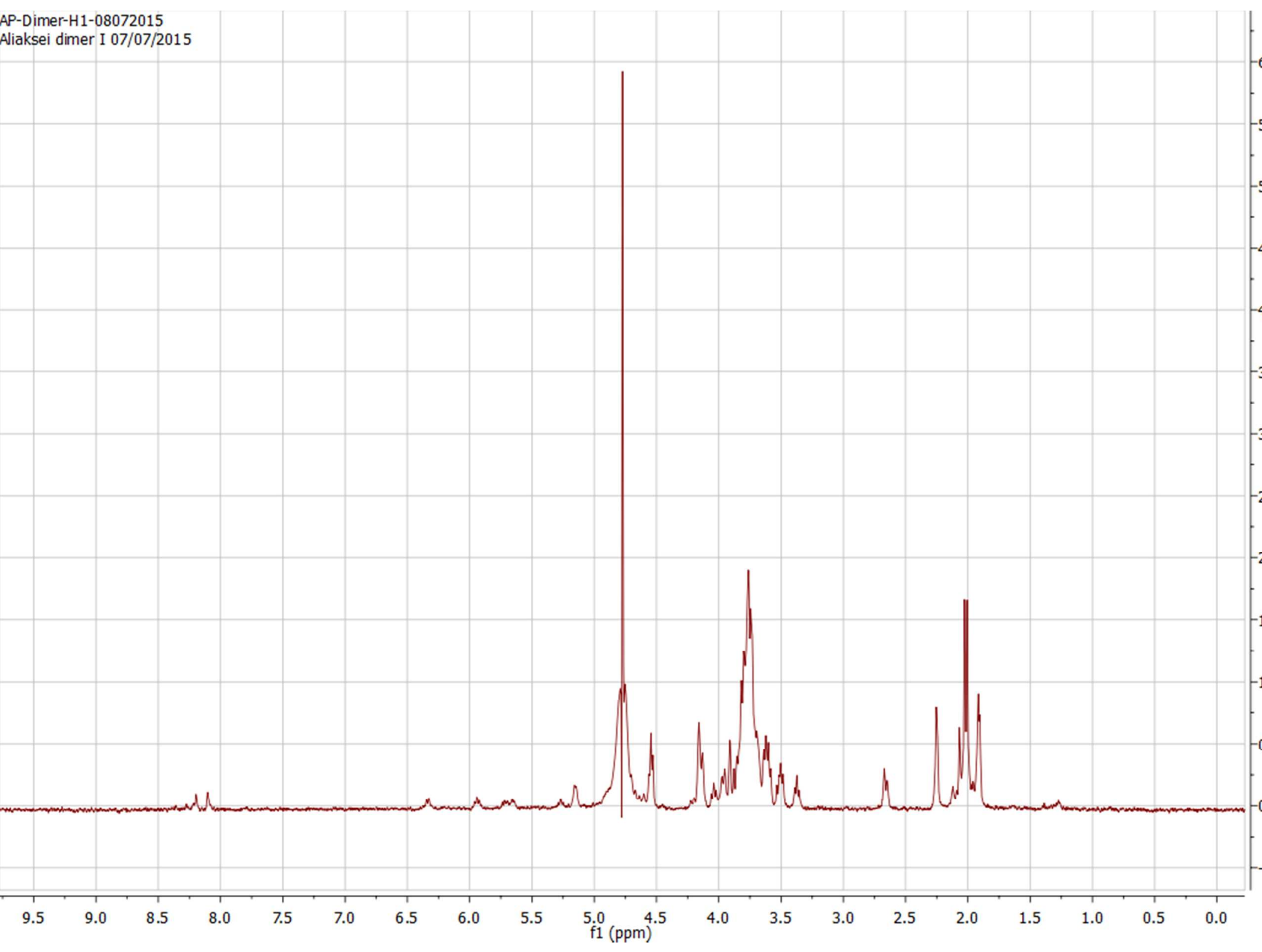


